\title{
MicroRNA-206 inhibits the viability and migration of human lung adenocarcinoma cells partly by targeting MET
}

\author{
XI CHEN ${ }^{*}$, ZHONG-KAI TONG ${ }^{*}$, JIAN-YA ZHOU, YA-KE YAO, SHU-MENG ZHANG and JIAN-YING ZHOU \\ Department of Respiratory Diseases, Thoracic Disease Diagnosis and Treatment Center, \\ The First Affiliated Hospital, School of Medicine, Zhejiang University, Hangzhou, Zhejiang 310003, P.R. China
}

Received March 31, 2015; Accepted May 13, 2016

DOI: $10.3892 / \mathrm{ol} .2016 .4735$

\begin{abstract}
MicroRNA (miRNA)-based targeting in cancer has emerged as a potential therapeutic strategy. miR-206 has recently been implicated in cancer. However, the role and molecular mechanism of miR-206 in lung adenocarcinoma are still unclear. The present study revealed that miR-206 was downregulated in human lung adenocarcinoma tissues. Overexpression of miR-206 in human lung adenocarcinoma-derived cells significantly inhibited cell viability and migration. Further experiments indicated that the overexpression of miR-206 decreased the expression of MET at the messenger RNA and protein levels via direct targeting of MET in a 3'-untranslated region-dependent manner. The knockdown of MET by small interfering RNA partly led to a phenocopy effect of miR-206. In conclusion, the present study identified miR-206 as a potential tumor suppressor of lung adenocarcinoma that exerts its functions, in part, by negative regulation of MET.
\end{abstract}

\section{Introduction}

Lung cancer is the leading cause of cancer-associated mortalities worldwide, and adenocarcinoma is one of the most common histological types of lung cancer in multiple countries (1). In the recent past, various major therapeutic advances have improved the prognosis of specific subgroups of patients (2). However, the 5-year survival rate of patients with lung cancer remains $<15 \%$ (3), and therefore, novel therapeutic strategies are required for better management of this disease.

Correspondence to: Professor Jian-Ying Zhou, Department of Respiratory Diseases, Thoracic Disease Diagnosis and Treatment Center, The First Affiliated Hospital, School of Medicine, Zhejiang University, 79 Qingchun Road, Hangzhou, Zhejiang 310003, P.R. China

E-mail: zjyhz@zju.edu.cn

*Contributed equally

Key words: lung cancer, miR-206, MET, tumor suppressor
MicroRNAs (miRNAs) are a class of small (18-25 nt), non-coding, endogenous RNAs that have been implicated in a wide range of cellular biological processes that involve the targeting of messenger RNAs (mRNAs) for either degradation or inhibition of translation $(4,5)$. Aberrant expression of miRNAs has been observed in lung cancer, including upregulation of miR-21, miR-17-92, miR-155 and miR-367 (6-8) and downregulation of let-7, miR-34b/c, miR-449a, miR-1 and miR-145 (8-12). This indicates that miRNAs can function as tumor suppressors and oncogenes in tumor development.

miR-206 was first identified as a skeletal muscle-specific miRNA that is involved in the process of skeletal muscle differentiation (13). The roles of miR-206 in breast cancer drew attention to the possibility of its anti-cancer activity, since miR-206 is downregulated in breast cancer, rhabdomyosarcoma, renal cell carcinoma, estrogen receptor $\alpha$-positive endometrioid adenocarcinoma, colorectal cancer, gastric cancer and lung cancer (14-21). Wu et al (22) noticed that the serum levels of miR-206 were significantly upregulated in the early stage of the tobacco-specific N-nitrosamine 4-(methylnitrosamino)-1-(3-pyridyl)-1-butanone-induced rat lung carcinogenesis, and downregulated at the late stage of lung carcinogenesis, which indicates that miR-206 may be associated with lung carcinogenesis. In addition, low expression of miR-206 was demonstrated to be correlated with tumor invasion and metastasis in individuals with lung cancer (20). However, the regulatory effects and mechanisms of miR-206 in human lung adenocarcinoma cell lines are not clear. In the present study, the function and targets of miR-206 in human lung adenocarcinoma cell lines were analyzed.

\section{Materials and methods}

Human tissue. Formalin-fixed and paraffin-embedded (FFPE) sections of paired lung adenocarcinoma tissues and adjacent normal tissues were obtained from patients who underwent radical resection for lung cancer. The samples were collected between October and December 2013 at The First Affiliated Hospital, School of Medicine, Zhejiang University (Zhejiang, China). The patients provided signed informed consent for participation in the study, which was approved by the Ethics Committee of Zhejiang University. The demographic and clinicopathological data are listed in Table I. 
Table I. Clinical features of the 12 patients with lung adenocarcinoma.

\begin{tabular}{|c|c|c|c|c|c|c|c|}
\hline Patient no. & Gender & $\begin{array}{c}\text { Age } \\
\text { (years) }\end{array}$ & Histological type & $\begin{array}{c}\text { Tobacco } \\
\text { smoking history }\end{array}$ & pTNM stage & Tumor grade & EGFR mutation \\
\hline 1 & M & 47 & Adenocarcinoma & Yes & T2aN0M0 & IB & Exon 19 deletion \\
\hline 2 & $\mathrm{~F}$ & 82 & Adenocarcinoma & No & T2aN0M0 & IB & Unknown \\
\hline 3 & $\mathrm{~F}$ & 41 & Adenocarcinoma & No & T2aN1M1 & IV & Unknown \\
\hline 4 & $\mathrm{~F}$ & 50 & Adenocarcinoma & No & T2aNOM0 & IB & Unknown \\
\hline 5 & $\mathrm{~F}$ & 47 & Adenocarcinoma & No & T2aN0M0 & IB & Unknown \\
\hline 6 & $\mathrm{~F}$ & 69 & Adenocarcinoma & No & T1aN2M0 & IIIA & Exon 19 deletion \\
\hline 7 & M & 46 & Adenocarcinoma & No & T2bN1M0 & IIB & Unknown \\
\hline 8 & $\mathrm{~F}$ & 73 & Adenocarcinoma & No & T2aN1M0 & IIA & No mutation \\
\hline 9 & $\mathrm{~F}$ & 50 & Adenocarcinoma & No & T1bN0M0 & IA & Unknown \\
\hline 10 & $\mathrm{~F}$ & 51 & Adenocarcinoma & No & T2bN3M0 & IIIB & No mutation \\
\hline 11 & M & 37 & Adenocarcinoma & No & T1bN0M0 & IA & Unknown \\
\hline 12 & M & 43 & Adenocarcinoma & No & T1bN2M0 & IIIA & Unknown \\
\hline
\end{tabular}

M, male; F, female; TNM, tumor-node-metastasis; EGFR, epidermal growth factor receptor.

Cell culture and reagents. The HCC827 and A549 cell lines were purchased from the Committee on Type Culture Collection of the Chinese Academy of Sciences (Shanghai, China). The PC-9 cell line was a gift from Dr Caicun Zhou (Department of Oncology, Shanghai Pulmonary Hospital, Shanghai, China) and was verified by short tandem repeats analysis. HCC827 and A549 cells were cultured in RPMI-1640 (Gibco; Thermo Fisher Scientific, Inc., Waltham, MA, USA) with 10\% fetal bovine serum (FBS; Gibco; Thermo Fisher Scientific, Inc.) at $37^{\circ} \mathrm{C}$ and $5 \% \mathrm{CO}_{2}$. The PC-9 cells were maintained in Dulbecco's modified Eagle's medium (DMEM; Gibco; Thermo Fisher Scientific, Inc.) supplemented with 10\% FBS.

Oligonucleotides and transfection. miR-206 mimics (double-stranded RNA oligonucleotides) and a negative control (NC) duplex that lacks significant homology to all known human sequences were purchased from Shanghai GenePharma Co., Ltd. (Shanghai, China). Small interfering RNA (siRNA) targeting MET (si-MET) and NC siRNA were purchased from Shanghai GenePharma Co., Ltd. The sequences are listed in Table II. The transfection was performed using Lipofectamine 2000 reagent (Invitrogen; Thermo Fisher Scientific, Inc.) according to the manufacturer's protocol.

Cell viability assay. The day prior to transfection, 3,000 cells/well were plated in 96-well plates. Upon overnight incubation, the cells were transfected with miR-206 mimics or with the NC miRNA at 20 or 40-nM concentration. After the culture period, $10 \mu \mathrm{l}$ cell counting solution (water-soluble tetrazolium-8; Dojindo Molecular Technologies, Inc., Kumamoto, Japan) was added to each well, followed by an additional incubation for $2 \mathrm{~h}$ at $24 \mathrm{~h}$ post-transfection, $1.5 \mathrm{~h}$ at $48 \mathrm{~h}$ post-transfection or $1 \mathrm{~h}$ at $72 \mathrm{~h}$ post-transfection. The absorbance of the solution was measured spectrophotometrically at $450 \mathrm{~nm}$ with an MRX II absorbance reader (Dynex Technologies, Chantilly, VA, USA). Each experiment was conducted three times in triplicate.
Cell migration assays. Transwell chambers $(8-\mu \mathrm{m}$ pore size; EMD Millipore, Billerica, MA, USA) were used to determine the migration of tumor cells. A total of $5 \times 10^{5}$ cells were resuspended in $0.2 \mathrm{ml}$ fresh medium without FBS $48 \mathrm{~h}$ after transfection, and then added to the inserts. Next, $0.6 \mathrm{ml}$ culture medium with $10 \%$ FBS was added to the lower compartment. After $24 \mathrm{~h}$, the non-migrating cells and culture medium were removed using cotton buds, while the cells on the lower surface of the inserts were fixed and stained with $0.1 \%$ crystal violet. Four random fields per insert were counted. The experiment was conducted three times in triplicate.

Cell apoptosis assay. Cell apoptosis was detected with an annexin V-fluorescein isothiocyanate (FITC) apoptosis detection kit (BD Biosciences, Franklin Lakes, NJ, USA). The cells were harvested $72 \mathrm{~h}$ after NC or miR-206 treatment. The cells were then washed twice with pre-chilled phosphate-buffered saline and resuspended in $500 \mu \mathrm{l}$ binding buffer at a concentration of $1 \times 10^{6}$ cells $/ \mathrm{ml}$. Then, cells were stained with $5 \mu 1$ annexin V-FITC and $5 \mu \mathrm{l}$ propidium iodide for $10 \mathrm{~min}$ in the dark. The apoptosis analysis was performed by the BD FACS Verse flow cytometer with CellQuest Pro 6.0 software (BD Biosciences).

Reverse transcription-quantitative polymerase chain reaction $(R T-q P C R)$. Total RNA was extracted from the cultured cells with TRIzol reagent (Invitrogen; Thermo Fisher Scientific, Inc.). RNA was reverse transcribed into complementary DNA (cDNA) using PrimeScript ${ }^{\mathrm{TM}}$ RT reagent kit (Takara Biotechnology Co., Ltd., Dalian, China). miRNAs isolated from FFPE tissues were extracted using the RNeasy FFPE kit (Qiagen GmbH, Hilden, Germany). miRNAs that were isolated from the cultured cells were extracted with RNAiso Plus (Takara Biotechnology Co., Ltd.) and reverse transcribed into cDNA using an RT kit (Qiagen $\mathrm{GmbH}$ ). PCR amplification and detection were performed on a 7500 Fast Real-Time PCR System (Applied Biosystems; Thermo Fisher Scientific, Inc.) using miScript SYBR Green PCR kit (Qiagen GmbH). 
Table II. Sequences of the oligonucleotides used in the present study.

\begin{tabular}{ll}
\hline Name & \multicolumn{1}{c}{ Sequence (5'-3') } \\
\hline miR-206 mimics & UGGAAUGUAAGGAAGUGUGUGG \\
& ACACACUUCCUUACAUUCCAUU \\
si-MET & GGAGGUGUUUGGAAAGAUAdTdT \\
& UAUCUUUCCAAACACCUCCdTdT \\
NC & UUCUCCGAACGUGUCACGUTT \\
& ACGUGACACGUUCGGAGAATT \\
GAPDH F & GGTCTCCTCTGACTTCAACA \\
GAPDH R & AGCCAAATTCGTTGTCATAC \\
MET F & GTTTGTCCACAGAGACTTGGCTG \\
MET R & ATCCACTTCACTGGCAGCTTTG
\end{tabular}

$\mathrm{F}$, forward; R, reverse; miR, microRNA; si, small interfering; GAPDH, glyceraldehyde 3-phosphate dehydrogenase; NC, negative control.

The amplification protocol was as follows: Initial denaturation $95^{\circ} \mathrm{C}$ for $30 \mathrm{sec}$, and then 40 cycles of denaturation at $95^{\circ}$ for $5 \mathrm{sec}$, annealing and extension at $60^{\circ} \mathrm{C}$ for $34 \mathrm{sec}$. The relative amounts of mRNA and miRNA gene transcripts were normalized to the levels of glyceraldehyde-3-phosphate dehydrogenase (GAPDH) and RNA, U6 small nuclear 2 (RNU6-2). The sequences of the primers for GAPDH and MET are listed in Table II. The primers for RNU6-2 and miR-206 were purchased from Qiagen $\mathrm{GmbH}$.

Vector construction and dual-luciferase reporter assay. The 3'-untranslated regions (UTRs) and the mutant 3'-UTR of MET, which contained putative binding sites for miR-206, were cloned downstream of the pmirGLO Dual-Luciferase miRNA Target Expression vector (Promega Corporation, Madison, WI, USA). The cells were plated in 24-well plates and were transfected with the constructed luciferase vector (100 ng) and $40 \mathrm{nM}$ miR-206 or NC. The relative luciferase activity was measured $48 \mathrm{~h}$ after transfection as described previously (23).

Immunoblotting. Following the various treatments, the cells were harvested, lysed and quantified. Equivalent quantities $(50 \mu \mathrm{g})$ of protein were separated by $8 \%$ sodium dodecyl sulfate-polyacrylamide gel electrophoresis and transferred onto polyvinylidene difluoride membranes. Membranes were blocked for $1 \mathrm{~h}$ with 5\% non-fat milk and then incubated overnight with a primary rabbit polyclonal antibody against MET (1:1,000 dilution; catalog no., 4560; Cell Signaling Technology, Inc., Danvers, MA, USA) and a rabbit polyclonal antibody against $\beta$-actin (1:2,000 dilution; catalog no., sc-130656; Santa Cruz Biotechnology, Inc., Dallas, TX, USA). Next, the membranes were incubated with a chicken anti-rabbit horseradish peroxidase-conjugated secondary antibody (catalog no., sc-516087, Santa Cruz Biotechnology, Inc.) at a 1:2,000 dilution for $2 \mathrm{~h}$. Immunoreactive bands were detected with an enhanced chemiluminescence system (Pierce; Thermo Fisher Scientific, Inc.) as described previously (23).

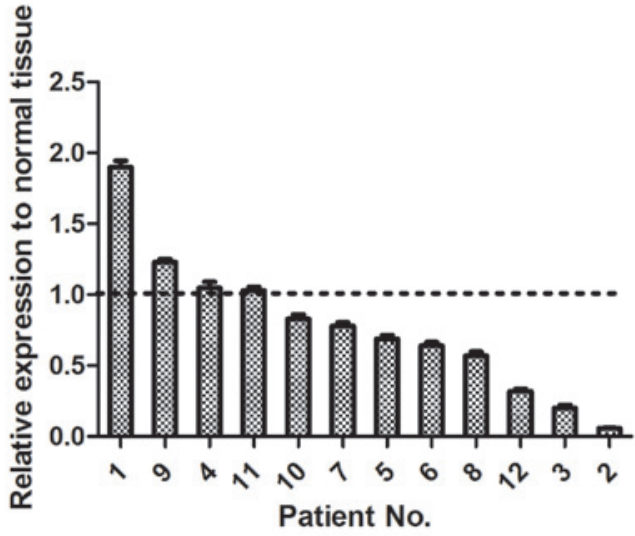

Figure 1. Expression of miR-206 in human lung adenocarcinoma. miR-206 expression was detected in 12 human lung adenocarcinoma tissues by reverse transcription-quantitative polymerase chain reaction. RNA, U6 small nuclear 2 was used as an internal control. The results were standardized to the paired normal tissue. Each experiment was performed three times in triplicate. The data are presented as the mean \pm standard deviation. $\mathrm{miR}$, microRNA.

Statistical analysis. All data are presented as the mean \pm standard deviation of three independent experiments. All statistical analyses were performed using SPSS 16.0 statistical software (SPSS, Inc., Chicago, IL, USA). P $<0.05$ was considered to indicate a statistically significant difference according to Student's $t$-test.

\section{Results}

miR-206 was frequently downregulated in lung adenocarcinoma. In the present study, the expression levels of miR-206 were detected in 12 pairs of human lung adenocarcinoma tissues and adjacent normal tissues. In total, 8 of 12 (75\%) lung adenocarcinoma tissues displayed a decreased expression of miR-206 compared with adjacent normal tissues (Fig. 1). This indicated that miR-206 is frequently downregulated in human lung adenocarcinoma.

Overexpression of miR-206 inhibited the viability of lung adenocarcinoma cells in vitro. In order to determine if miR-206 could function as a tumor suppressor in human lung adenocarcinoma cells, synthetic miR-206 mimics and NC miRNA were independently transfected into A549, PC-9 and HCC 827 cells. The overexpression of miR-206 exerted a potent inhibitory effect in a time- and dose-dependent manner. Compared with the NC group, miR-206 caused an increased percentage of inhibition of cell viability at a concentration of $40 \mathrm{nM}$ in the three cell lines tested at 48 or $72 \mathrm{~h}$ after transfection (Fig. 2). These data suggested that miR-206 negatively modulates the viability of lung adenocarcinoma cells. The apoptosis analysis by flow cytometry revealed that the early apoptosis rate was not affected in A549 or HCC827 cells, whereas the late apoptosis rate was higher in $\mathrm{HCC} 827$ cells following miR-206 treatment (Fig. 3).

Forced expression of miR-206 repressed the migration of lung adenocarcinoma cells. To better understand the function of miR-206 in lung adenocarcinoma, the present study tested 

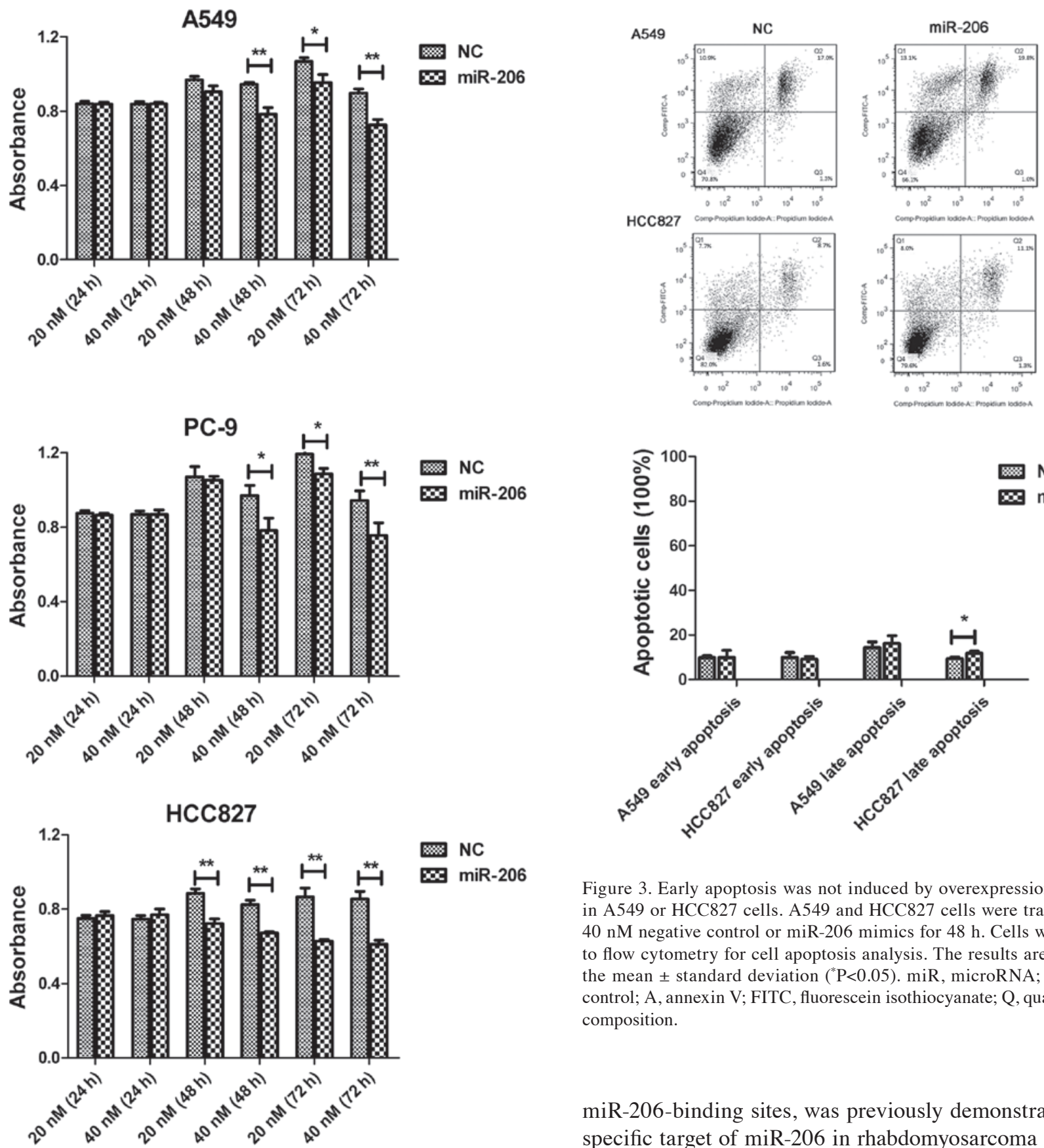

Figure 3. Early apoptosis was not induced by overexpression of miR-206 in A549 or HCC827 cells. A549 and HCC827 cells were transfected with $40 \mathrm{nM}$ negative control or miR-206 mimics for $48 \mathrm{~h}$. Cells were subjected to flow cytometry for cell apoptosis analysis. The results are presented as the mean \pm standard deviation ( $(\mathrm{P}<0.05)$. miR, microRNA; NC, negative control; A, annexin V; FITC, fluorescein isothiocyanate; Q, quadrant; Comp, composition.

Figure 2. Overexpression of miR-206 inhibited the viability of lung adenocarcinoma cells in vitro. A549, PC-9 and HCC827 cells were transfected with different concentrations of negative control or miR-206 mimics for 24,48 or $72 \mathrm{~h}$. Cell viability was determined using the water-soluble tetrazolium- 8 assay. Each experiment was performed three times in triplicate. The results are presented as the mean \pm standard deviation $\left({ }^{*} \mathrm{P}<0.05,{ }^{* *} \mathrm{P}<0.01\right)$. miR, microRNA; NC, negative control.

whether miR-206 could affect the migration of lung adenocarcinoma cells. A549, PC-9 and HCC827 cells were transfected with miR-206 mimics. The forced expression of miR-206 caused significant inhibition of cell migration compared with the control in all three cell lines (Fig. 4).

Overexpression of miR-206 downregulated the expression of MET in lung adenocarcinoma cells through targeting its 3'-UTR. The mRNA of MET, whose 3'-UTR contains

miR-206-binding sites, was previously demonstrated to be a specific target of miR-206 in rhabdomyosarcoma (24). In the present study, it was observed that MET was downregulated significantly at both the mRNA and protein levels (Fig. 5A and B). A luciferase reporter assay confirmed that MET was a direct target of miR-206 in human lung adenocarcinoma cells (Fig. 5C and D). These results suggested a targeted downregulation of MET by miR-206 in lung adenocarcinoma.

miR-206 triggered the inhibition of cell viability and migration in lung adenocarcinoma cells in part via targeting MET. To determine whether the downregulation of MET was involved in the miR-206-mediated inhibition of cell viability and migration, the physiological function of MET was evaluated by an RNA interference approach. The knockdown of MET suppressed cell viability and migration, but these effects were not as remarkable as those observed upon miR-206 overexpression (Fig. 6). These findings indicated that the anti-tumor effect of miR-206 is partly dependent on the targeted regulation of MET. 
A
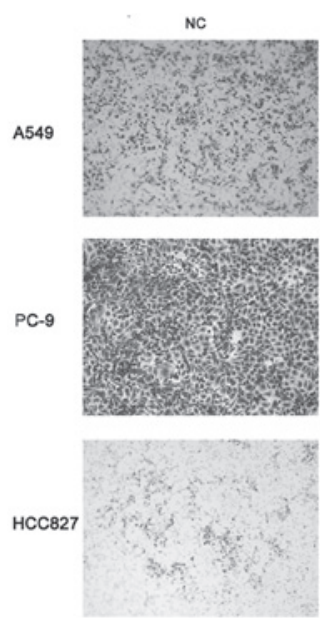
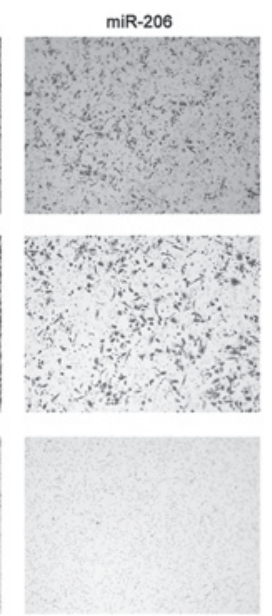

B

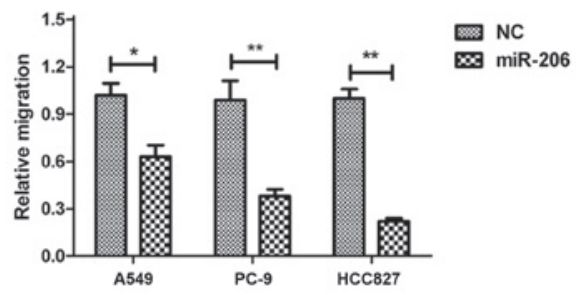

Figure 4. Forced expression of miR-206 repressed the migration of lung adenocarcinoma cells. (A) Representative micrographs of the cell migration assay (magnification, $\mathrm{x} 100)$ and (B) quantification from three independent experiments. The results are presented as the mean \pm standard deviation ("P $<0.05$, $\left.{ }^{* *} \mathrm{P}<0.01\right)$. miR, microRNA; NC, negative control.

A

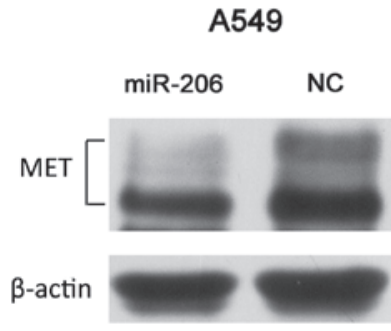

B

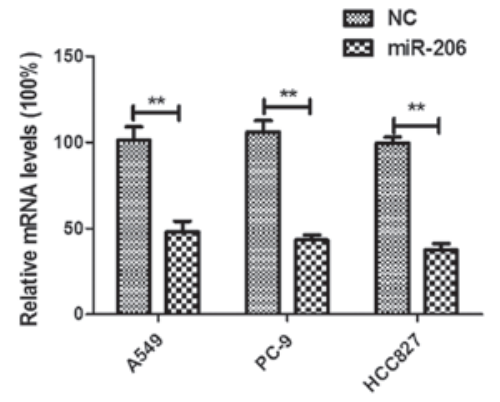

C

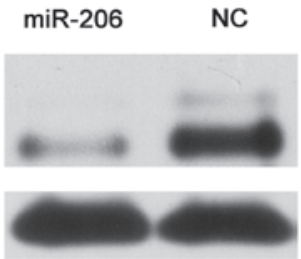

D 5' UCACCCAUUAGgUaACAUUCCC $3^{\prime}$ Wide-type UTR

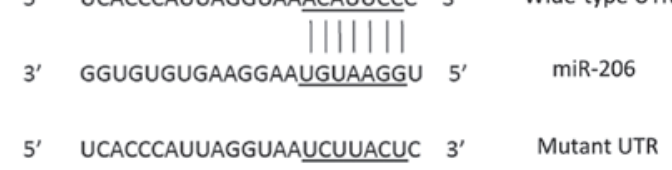

Figure 5. Overexpression of miR-206 resulted in the downregulation of MET expression in lung adenocarcinoma cells through the targeting of its 3'-UTR. (A) A549, PC-9 and HCC 827 cells were transfected with $40 \mathrm{nM} \mathrm{NC}$ or miR-206 mimics for $48 \mathrm{~h}$. The cell lysates were harvested, and the phosphorylation of the indicated proteins was determined by western blotting. Three independent experiments were performed. (B) A549, PC-9 and HCC827 cells were transfected with $40 \mathrm{nM} \mathrm{NC}$ or miR-206 mimics for $48 \mathrm{~h}$. Subsequently, RNA was extracted and reverse transcription-quantitative polymerase chain reaction analysis was conducted to determine the relative expression of MET. Data were normalized to glyceraldehyde 3-phosphate dehydrogenase. Each experiment was performed three times in triplicate. The results are presented as the mean $\pm \mathrm{SD}\left({ }^{* *} \mathrm{P}<0.01\right)$. (C) Overexpression of miR-206 suppressed pmirGLO-MET-3'-UTR-wild-type firefly luciferase activity but exerted no effect on the mutant construct in A549 cells. Each experiment was performed three times in triplicate. The values were normalized to the internal Renilla luciferase control. The results are presented as the mean $\pm \mathrm{SD}\left({ }^{* *} \mathrm{P}<0.01\right)$. (D) miR-206 target sites and substitution of nucleotides at the target sites in the MET 3'-UTR. miR, microRNA; NC, negative control, WT, wild-type; Mut, mutant; UTR, untranslated region; SD, standard deviation.

\section{Discussion}

In recent years, the idea of targeted molecular therapy has become one of the most attractive topics in the field of human cancer treatment (3). Thus, the identification of the molecular pathogenesis of cancer is crucial for the development of effective therapeutic approaches. Emerging evidence suggests that the dysregulation of miRNAs plays a pivotal role in 


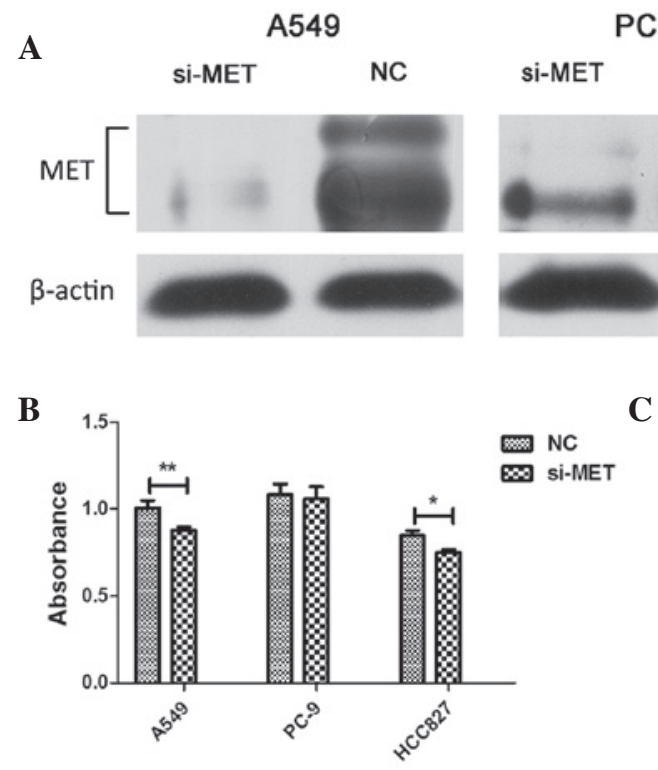

\section{C}

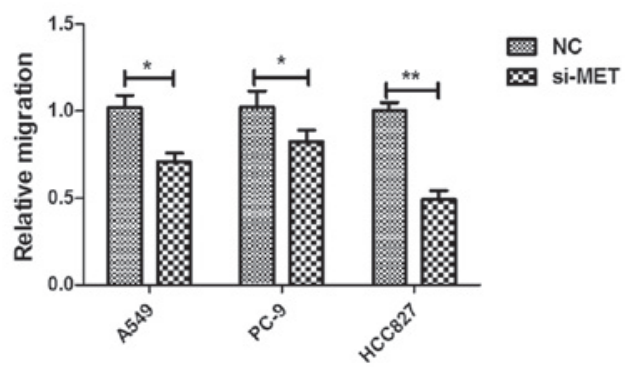

D

NC

A549

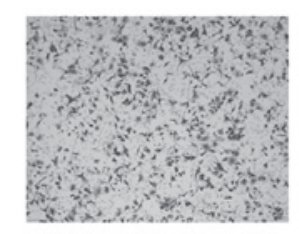

Si-MET

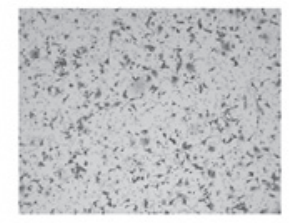

PC-9
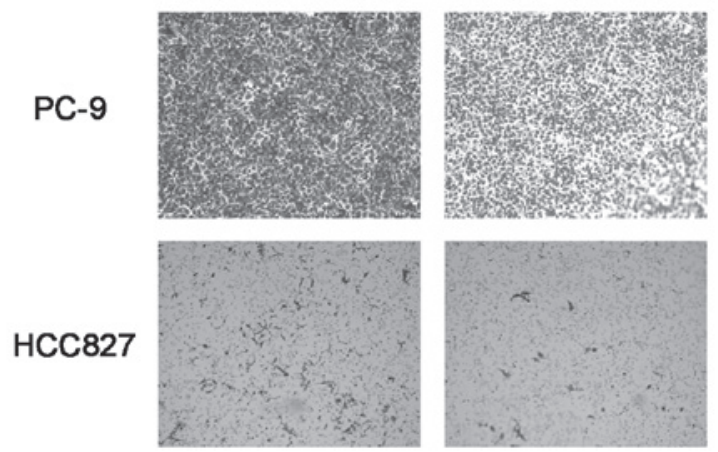

Figure 6. Knockdown of MET reduced the cell viability and migration of lung adenocarcinoma cells. (A) A549, PC-9 and HCC 827 cells were transfected with $40 \mathrm{nM} \mathrm{NC}$ or si-MET for $48 \mathrm{~h}$. The cell lysates were harvested, and the phosphorylation of the indicated proteins was determined by western blotting. Three independent experiments were performed. (B) A549, PC-9 and HCC827 cells were transfected with $40 \mathrm{nM}$ NC or si-MET for 48 h. Cell viability was determined using water-soluble tetrazolium- 8 assays. Each experiment was performed three times in triplicate. The results are presented as the mean \pm SD $\left({ }^{*} \mathrm{P}<0.05,{ }^{* *} \mathrm{P}<0.01\right)$. (C) Quantification from three independent experiments and (D) representative micrographs of the cell migration assay (magnification, $\mathrm{x} 100)$. The results are presented as the mean $\pm \mathrm{SD}\left({ }^{*} \mathrm{P}<0.05,{ }^{* *} \mathrm{P}<0.01\right)$. si, small interfering; NC, negative control; SD, standard deviation.

the pathogenesis of human cancer development through the targeting of a variety of important molecules (25). Previous studies have demonstrated that miR-206 is downregulated in lung cancer, which is correlated with tumor invasion and metastasis (20). However, the functional role of miR-206 in lung adenocarcinoma is largely unknown. In the present study, the functional characterization and the mechanism of action of miR-206 in human lung adenocarcinoma were investigated. It was observed that tumor tissues from patients with lung adenocarcinoma exhibited a decrease in miR-206 expression. Furthermore, miR-206 expression caused significant suppression of cell viability and migration in lung adenocarcinoma cells in vitro. These results indicate that miR-206 may serve as a tumor-suppressor gene in lung adenocarcinoma.

MET is a receptor tyrosine kinase that is dysregulated in multiple cancer types, including lung cancer (26).
Overexpression of MET protein is detected in 36.0-72.3\% of lung adenocarcinoma tissues, and is associated with tumor metastasis and poor prognosis (27-29). Silencing or inactivation of MET has been demonstrated to be important for cell viability in vitro, as well as for cell motility and migration $(11,30)$. In rhabdomyosarcoma, MET was demonstrated to be a direct target of miR-206 (15). In the present study, MET was downregulated by miR-206 in lung adenocarcinoma cells at both the mRNA and protein levels. The luciferase assay indicated that MET is a target of miR-206, as the specific knockdown of MET by siRNA led to a partial phenocopy of the inhibitory effect of cell viability and migration inhibition that was observed with miR-206 overexpression. Together with the present findings, these results suggested that MET acts as a potential oncogene and is involved in the anti-tumor effects of miR-206. 
In conclusion, the present study confirms that miR-206 is frequently downregulated in lung adenocarcinoma. The ectopic expression of miR-206 can exert an inhibitory effect on cell viability and migration of lung adenocarcinoma cells, in part, by targeting MET. These data suggest that miR-206 serves as a potential tumor suppressor and may be developed as a novel therapeutic strategy for patients with lung adenocarcinoma.

\section{Acknowledgements}

The present study was supported by grants from the National Natural Science Foundation of China (Beijing, China; grant no. 81101768), the State Scholarship Fund of China (Beijing, China; grant no. 201308330145) and the Medicine and Health Sci-Tech Project of Zhejiang Province (Hangzhou, China; grant no. 2015KYA074).

\section{References}

1. Torre LA, Bray F, Siegel RL, Ferlay J, Lortet-Tieulent J and Jemal A: Global cancer statistics, 2012. CA Cancer J Clin 65 87-108, 2015

2. Cancer Genome Atlas Research Network: Comprehensive molecular profiling of lung adenocarcinoma. Nature 511: 543-550, 2014

3. Moreira AL and Eng J: Personalized therapy for lung cancer. Chest 146: 1649-1657, 2014.

4. Bartel DP: MicroRNAs: Genomics, biogenesis, mechanism, and function. Cell 116: 281-297, 2004.

5. Bartel DP. MicroRNAs: target recognition and regulatory functions. Cell 136:215-33, 2009.

6. Yang M, Shen H, Qiu C, Ni Y, Wang L, Dong W, Liao Y and Du J: High expression of miR-21 and miR-155 predicts recurrence and unfavourable survival in non-small cell lung cancer. Eur J Cancer 49: 604-615, 2013.

7. Hayashita Y, Osada H, Tatematsu Y, Yamada H, Yanagisawa K, Tomida S, Yatabe Y, Kawahara K, Sekido Y and Takahashi T: A polycistronic microRNA cluster, miR-17-92, is overexpressed in human lung cancers and enhances cell proliferation. Cancer Res 65: 9628-9632, 2005.

8. Campayo M, Navarro A, Viñolas N, Diaz T, Tejero R, Gimferrer JM, Molins L, Cabanas ML, Ramirez J, Monzo M and Marrades R: Low miR-145 and high miR-367 are associated with unfavourable prognosis in resected nonsmall cell lung cancer. Eur Respir J 41: 1172-1178, 2013.

9. Osada H and Takahashi T: let-7 and miR-17-92: Small-sized major players in lung cancer development. Cancer Sci 102: 9-17, 2011.

10. Nadal E, Chen G, Gallegos M, Lin L, Ferrer-Torres D, Truini A, Wang Z, Lin J, Reddy RM, Llatjos R, et al: Epigenetic inactivation of microRNA-34b/c predicts poor disease-free survival in early stage lung adenocarcinoma. Clin Cancer Res 19: 6842-6852, 2013.

11. Luo W, Huang B, Li Z, Li H, Sun L, Zhang Q, Qiu X and Wang E: MicroRNA-449a is downregulated in non-small cell lung cancer and inhibits migration and invasion by targeting c-Met. PLoS One 8: e64759, 2013.

12. Nasser MW, Datta J, Nuovo G, Kutay H, Motiwala T, Majumder S, Wang B, Suster S, Jacob ST and Ghoshal K: Downregulation of micro-RNA-1 (miR-1) in lung cancer. Suppression of tumorigenic property of lung cancer cells and their sensitization to doxorubicin-induced apoptosis by miR-1. J Biol Chem 283: 33394-33405, 2008
13. Rao PK, Kumar RM,Farkhondeh M, Baskerville S and Lodish HF: Myogenic factors that regulate expression of muscle-specific microRNAs. Proc Natl Acad Sci USA 103: 8721-8726, 2006.

14. Kondo N, Toyama T, Sugiura H, Fujii Y and Yamashita H: miR-206 Expression is downregulated in estrogen receptor alpha-positive human breast cancer. Cancer Res 68: 5004-5008, 2008.

15. Taulli R, Bersani F, Foglizzo V, Linari A, Vigna E, Ladanyi M, Tuschl $\mathrm{T}$ and Ponzetto $\mathrm{C}$ : The muscle-specific microRNA miR-206 blocks human rhabdomyosarcoma growth in xenotransplanted mice by promoting myogenic differentiation. J Clin Invest 119: 2366-2378, 2009.

16. Hidaka H, Seki N, Yoshino H, Yamasaki T, Yamada Y, Nohata N, Fuse M, Nakagawa $M$ and Enokida H: Tumor suppressive microRNA-1285 regulates novel molecular targets: Aberrant expression and functional significance in renal cell carcinoma. Oncotarget 3: 44-57, 2012.

17. Chen X, Yan Q, Li S, Zhou L, Yang H, Yang Y, Liu X and Wan X: Expression of the tumor suppressor miR-206 is associated with cellular proliferative inhibition and impairs invasion in ER $\alpha$-positive endometrioid adenocarcinoma. Cancer Lett 314: 41-53, 2012.

18. Vickers MM, Bar J, Gorn-Hondermann I, Yarom N, Daneshmand M, Hanson JE, Addison CL, Asmis TR, Jonker DJ, Maroun J, et al: Stage-dependent differential expression of microRNAs in colorectal cancer: Potential role as markers of metastatic disease. Clin Exp Metastasis 29: 123-132, 2012.

19. Zhang L, Liu X, Jin H, Guo X, Xia L, Chen Z, Bai M, Liu J, Shang X, Wu K, et al: miR-206 inhibits gastric cancer proliferation in part by repressing cyclinD2. Cancer Lett 332: 94-101, 2013.

20. Wang X, Ling C, Bai Y and Zhao J: MicroRNA-206 is associated with invasion and metastasis of lung cancer. Anat Rec (Hoboken) 294: 88-92, 2011.

21. Georgantas RW III, Streicher K, Luo X, Greenlees L, Zhu W, Liu Z, Brohawn P, Morehouse C, Higgs BW, Richman L, et al: MicroRNA-206 induces G1 arrest in melanoma by inhibition of CDK4 and Cyclin D. Pigment Cell Melanoma Res 27: 275-286, 2014.

22. Wu J, Yang T, Li X, Yang Q, Liu R, Huang J, Li Y, Yang C and Jiang Y: Alteration of serum miR-206 and miR-133b is associated with lung carcinogenesis induced by 4-(methylnitrosamino)-1-(3pyridyl)-1-butanone. Toxicol Appl Pharmacol 267: 238-246, 2013.

23. Zhou JY, Chen X, Zhao J, Bao Z, Chen X, Zhang P, Liu ZF and Zhou JY: MicroRNA-34a overcomes HGF-mediated gefitinib resistance in EGFR mutant lung cancer cells partly by targeting MET. Cancer Lett 351: 265-271, 2014.

24. Yan D, Dong Xda E, Chen X, Wang L, Lu C, Wang J, Qu J and Tu L: MicroRNA-1/206 targets c-Met and inhibits rhabdomyosarcoma development. J Biol Chem 284: 29596-29604, 2009.

25. Croce CM and Calin GA: miRNAs, cancer, and stem cell division. Cell 122: 6-7, 2005.

26. Skead G and Govender D: Gene of the month: MET. J Clin Pathol 68: 405-409, 2015.

27. Nakamura Y, Niki T, Goto A, Morikawa T, Miyazawa K, Nakajima $\mathrm{J}$ and Fukayama $\mathrm{M}$ : c-Met activation in lung adenocarcinoma tissues: An immunohistochemical analysis. Cancer Sci 98: 1006-1013, 2007.

28. Ma PC, Jagadeeswaran R, Jagadeesh S, Tretiakova MS, Nallasura V, Fox EA, Hansen M, Schaefer E, Naoki K, Lader A, et al: Functional expression and mutations of c-Met and its therapeutic inhibition with SU11274 and small interfering RNA in non-small cell lung cancer. Cancer Res 65: 1479-1488, 2005.

29. Ichimura E, Maeshima A, Nakajima T and Nakamura T: Expression of c-met/HGF receptor in human non-small cell lung carcinomas in vitro and in vivo and its prognostic significance. Jpn J Cancer Res 87: 1063-1069, 1996.

30. Zillhardt M, Christensen JG and Lengyel E: An orally available small-molecule inhibitor of c-Met, PF-2341066, reduces tumor burden and metastasis in a preclinical model of ovarian cancer metastasis. Neoplasia 12: 1-10, 2010. 